\title{
O ensino de doenças microbianas para o aluno com surdez: um diálogo possível com a utilização de material acessível
}

\author{
Roberta Silva Rizzo* \\ Lydia Dayanne Maia Pantoja** \\ Jeanne Barros Leal de Pontes Medeiros** \\ Germana Costa Paixão****
}

\section{Resumo}

A educação especial ainda é um grande desafio. Neste sentido, muitas metodologias e recursos didáticos pedagógicos, têm sido implantados para favorecer o processo de ensino e aprendizagem em diferentes disciplinas, com destaque para ensino em $\mathrm{Ci}$ ências. Compreendendo a importância da temática relacionada às doenças causadas por micro-organismos, o jogo intitulado "Conhecendo o mundo invisível - desafio de sinais" trata-se de uma proposta didática, para informar e esclarecer alunos surdos do Ensino Fundamental sobre o assunto, utilizando ferramentas visuais. Para tanto, sua construção tomou como documento norteador os Parâmetros Curriculares Nacionais (PCNs) de Ciências Naturais, com o desenvolvimento da arte gráfica do jogo, constituído de materiais simples e de baixo custo. Como resultado obteve-se um recurso pedagógico com sinais da Língua Brasileira de Sinais (Libras) que atende aos objetivos e aborda conteúdos que permeiam por três eixos temáticos dos PCNs. Portanto, trata-se de uma sugestáo para trabalhar os conteúdos microbianos de modo menos abstrato e mais atraente aos alunos com surdez, constituindo uma possibilidade de abordar temas previstos no currículo de Ciências, de maneira a subsidiar ensino e o processo de aprendizagem voltados para a alfabetizaçáo científica e a apropriação de conhecimentos, relacionados ao desenvolvimento de competências e habilidades necessárias ao mundo atual.

Palavras-chave: Ensino de Ciências; Jogo didático; Libras.

\footnotetext{
* Graduada em Ciências Biológicas pela Universidade Estadual do Ceará (UECE). Fortaleza, Ceará, Brasil.

** Doutoranda em Engenharia Civil (Saneamento Ambiental) pela Universidade Federal do Ceará. Fortaleza, Ceará, Brasil.

*** Professora do Curso de Ciências Biológicas da Universidade Estadual do Ceará (UECE). Fortaleza, Ceará, Brasil.

**** Professora do Curso de Ciências Biológicas da Universidade Estadual do Ceará (UECE). Fortaleza, Ceará, Brasil.
} 


\section{Microbial Diseases in the Teaching-learning Process of Deaf People: A Possible Dialogue}

\section{Abstract}

Special Education remains a major challenge in society. Thus, many methodologies and didactic-pedagogic resources have been deployed in order to further the teaching and learning process in different subjects, with emphasis on Science teaching. By understanding the importance of diseases caused by microorganisms, the game titled "Knowing the unseen world - challenging signal" was conceived as a didactic proposal to inform and enlighten deaf students from Elementary School on this subject, applying visual tools. Therefore, its construction took the National Curriculum Parameters (NCP) for Natural Sciences as a guiding, and the development of the graphic art consisted of simple and low cost materials. As a result, it was obtained a teaching resource with signs of LIBRAS that meets the objectives and contents that addresses of the three main themes of the NCPs. So, this is a suggestion to work the microbial content in a less abstract and more attractive form to deaf students, providing an opportunity to address issues specified in science curriculum in order to support the teaching-learning process focused on scientific literacy and the appropriation of knowledge related to the development of skills and abilities necessary to the current society.

Keywords: Science education; Educational game; Libras.

\section{Introdução}

A qualidade da educaçáo especial brasileira tem se mostrado um reflexo da junção de diversos problemas de cunho político, econômico e social, culminando com mudanças que têm ocorrido de maneira relativamente lenta ao longo dos anos.

Neri e Soares (2004), de acordo com o censo realizado pelo Instituto Brasileiro de Geografia e Estatística (IBGE), no ano 2000, afirmam que já existiam no Brasil, naquela época, cerca de 24 milhóes de pessoas portadoras de necessidades especiais, correspondendo a aproximadamente $14 \%$ de nossa população, sendo 5,7 milhốes com deficiência auditiva. Enquanto, segundo os dados do último censo do IBGE (2010), o número de portadores de necessidades especiais aumentou consideravelmente, ultrapassando os 45 milhôes de brasileiros, ou seja, quase $24 \%$ da população. Destes, em torno de 9,7 milhôes, são pessoas com algum grau de comprometimento auditivo, geralmente excluídas de diversas formas e dimensóes da vida social e produtiva do país.

Diante dos dados citados, a educaçáo de alunos com surdez deve ser um assunto prioritário e que leve a reflexóes pelas dificuldades que impóe e por suas limitaçôes, assim propostas educacionais direcionadas para surdos devem ter como objetivo principal o desenvolvimento pleno de suas capacidades, muito embora isso não seja observado com frequência na realidade atual. 
Com a promulgação da Lei de Diretrizes e Bases da Educação Nacional (LDB), a inclusão social de portadores de necessidades especiais, em escolas regulares, recebeu mais atenção e foi sendo ampliada (BRASIL, 1996). Mesmo com essa iniciativa, o que se observa é que a inclusáo encontra-se, ainda, desarticulada e desacompanhada de uma integraçáo entre os alunos com surdez e os ouvintes, e até mesmo entre aqueles e os profissionais da escola, considerando-se como um dos principais motivos a carência de práticas e materiais pedagógicos que favoreçam a sua ocorrência.

A preocupação em desenvolver atividades práticas que colaborem, efetivamente, para a aprendizagem, tanto da educaçáo especial, quanto do ensino regular, começou a ter presença marcante nos estabelecimentos de ensino e nos cursos de formação de professores ao longo dos últimos anos, tendo sido produzidos vários materiais didáticos desta tendência, especialmente no ensino de Ciências (COUTO; PORTUGAL, 2006; DECHICHI; SILVA; GOMIDE, 2008).

Dentro dessa temática, na educação básica, ainda percebemos o ensino de Ciências restrito às aulas expositivas com mínima participação dos alunos. E com relaçáo ao ensino de Microbiologia, especificamente, Cassanti (2007) afirma que o desafio se mostra ainda maior por ser uma ciência que se dedica ao estudo de organismos microscópicos (FERREIRA; PHILIPPSEN; ROCHA, 2006; MOURÃO; CAETANO, 2009; SILVA; OLIVEIRA; SOUZA, 2009).

Entretanto, a presença dos micro-organismos nos mais diversos locais do planeta de forma surpreendente tem sido conhecida nos últimos anos, participando de uma grande variedade de processos, alguns dos quais são fundamentais a manutenção da vida na Terra (TORTORA; FUNKE; CASE, 2005). A exploração desse aspecto tem sido pouco realizada no processo de ensino, sendo considerada como uma falha de muitos professores ao ensinar Microbiologia. Eles simplesmente não explicam que processos são estes, o porquê da importância destes micróbios, não chegando se quer a mencionar (CASSANTI, 2007).

Nicolau e Boas (2006) ressalvam a importância de compreender os diversos atributos dos micro-organismos, pois, segundo os autores, o conhecimento geral, global e não centralizado em uma característica estimula a criatividade e a curiosidade do aluno, tornando-o mais crítico.

A escassez de atividades, planos, estratégias que tornem as aulas mais dinâmicas para os alunos faz com que a percepção seja dificultada pelos estudantes, ficando a Microbiologia retida muitas vezes ao abstrato (CASSANTI, 2007).

Como muitas escolas náo dispóem de material adequado para uma melhor projeção dos micro-organismos, como laboratórios ou representaçôes concretas em três dimensóes de suas estruturas, o ensino acaba por se dar de forma defasada, sem que o aluno entenda o conhecimento que o professor está realmente tentando transmitir (SILVA; OLIVEIRA; SOUZA, 2009).

Assim, técnicas alternativas poderiam suprir essa defasagem durante a aula. A fabricação de modelos didáticos, por exemplo, com a devida utilização surgem como 
uma forma de alimentar a curiosidade dos alunos, forçando-os, de maneira positiva, a participar da aula, e, dessa forma, transmitir a devida importância dos micróbios (MOURÃO; CAETANO, 2009).

O fato da abordagem desses micro-organismos possuir diversos nomes específicos, muitas vezes dificulta a compreensão do conteúdo em sala de aula. Isso reforça a mudança do modelo de ensino das escolas, no qual as mesmas se tornam mais participativas, contextualizadas, inseridas na comunidade através das mais diversas áreas de conhecimento (FERREIRA; PHILIPPSEN; ROCHA, 2006). Especificamente, quando considerada a educação especial de surdos, identificamos uma escassez de sinais que contemplem termos científicos, o que amplia ainda mais as dificuldades em transmitir conceitos e termos tão específicos a esses alunos.

Paralelamente, nos Parâmetros Curriculares Nacionais (PCNs) do Ensino Fundamental, esses assuntos estão distribuídos amplamente nos eixos temáticos, principalmente em "Vida e ambiente", "Ser humano e saúde" e "Tecnologia e sociedade", demonstrando a relevância dessa área do conhecimento na formaçáo dos alunos.

Logo, considerar o desenvolvimento cognitivo dos estudantes, relacionado à suas experiências, sua idade, sua identidade cultural e social, e os diferentes significados e valores que as Ciências Naturais podem ter para eles, é essencial para que a aprendizagem seja significativa. Por meio de temas de trabalho, o ensino e o processo de aprendizagem, na área de Ciências, podem ser desenvolvidos dentro de contextos social e culturalmente relevantes, que potencializam a aprendizagem significativa (BRASIL, 1998). Tratando-se, portanto, de organizar atividades interessantes que permitam a exploração e a sistematização de conhecimentos compatíveis ao nível de desenvolvimento intelectual dos estudantes, em diferentes momentos do desenvolvimento.

Dentre os recursos didáticos disponíveis, os jogos podem se constituir como ferramentas valiosas de transcender as barreiras do simples processo de transmissão e recepção de conhecimentos. Sua utilização favorece a socialização de conhecimentos prévios num trabalho em grupo e a exploraçáo de diversos conteúdos de forma prazerosa (DOHME, 2003; ANTUNES, 2010; OLIVEIRA, 2010).

Enquanto, segundo Oliveira (2008), a respeito da utilização dos jogos na educaçáo de alunos surdos, a prática pedagógica, aliada ao uso de jogos, pode proporcionar um aprendizado significativo e prazeroso aos educandos surdos, por meio do qual desenvolvam sua autonomia e criatividade, na participação em diferentes atividades lúdicas, desenvolvidas na perspectiva da percepçáo visual do mundo.

Por tanto, diante da carência de materiais didáticos como este, o desenvolvimento de projetos de ensino voltados para essa perspectiva é de grande importância. Dentro deste contexto, a elaboração do jogo didático "Conhecendo um mundo invisível - desafio de sinais" é uma sugestão de instrumento pedagógico como alternativa para complementar o ensino de Ciências, em especial o conteúdo sobre doenças microbianas, em sala de aula. Destinado a alunos surdos do Ensino Fundamental, possui como diferenciais: a inserção de sinais em Libras em suas peças, uma linguagem de 
fácil compreensão, o baixo custo de confecção, permitindo uma maior acessibilidade a esses alunos, além de ter sido pensado de acordo com a Lei de Diretrizes e Bases do Ensino Nacional (LDBEN) (BRASIL, 1996) e produzido segundo as orientaçôes dos Parâmetros Curriculares Nacionais (PCNs).

\section{Metodologia}

De acordo com a forma de abordagem do problema, o enfoque desta pesquisa é essencialmente de natureza qualitativa, pois tenta entender os aspectos sociais implicados no objeto de estudo. Com frequência esse enfoque está baseado em métodos de coleta de dados sem medição numérica, como as descrições (SAMPIERI; COLLADO; LUCIO, 2006).

O jogo propriamente dito foi adaptado do brinquedo Imagem e Ação da empresa $\mathrm{GROW}^{\oplus}$, possuindo conteúdo e regras diferenciados do brinquedo original. A escolha dos modelos se deve ao fato de que para utilizá-lo é necessária comunicação visual, através de desenhos ou mímicas, fundamental para a pessoa com surdez. De acordo com Oliveira (2010), os sujeitos surdos encontram dificuldades com o uso do português escrito, e utilizam amplamente a visão em sua comunicação por meio de Libras, pois para o aluno com surdez, a percepçáo e a representaçáo do mundo se dão por meio dos componentes, visual e gestual.

A confecção do jogo foi realizada no Laboratório de Microbiologia (LAMIC) da Universidade Estadual do Ceará (UECE) com a colaboração de professores do Instituto Cearense de Educação de Surdos (ICES).

Buscou-se priorizar a utilização de materiais simples, acessíveis, de fácil aquisição, recicláveis, com boa durabilidade, baixo custo e de fácil manuseio. A arte gráfica foi desenvolvida através dos programas SketchUp (para modelagem 3D), Photoshop CS5 (edição de imagem) e PowerPoint (disposição das imagens).

Para a escolha do conteúdo, foram analisados os PCNs de Ciências Naturais do Ensino Fundamental, e escolhido o tema doenças humanas causadas por micro -organismos, devido à relevância do mesmo dentro do eixo temático Ser Humano e Saúde.

Após a seleção, o conteúdo foi distribuído em cinquenta cartas divididas em cinco temas: corpo humano, curiosidades, desafio, prevenção e sintomas. As informaçôes foram escritas com frases objetivas e condensadas a fim de proporcionar maior compreensão das informaçóes pelos alunos.

Por fim, o jogo foi doado para a brinquedoteca do Instituto Cearense de Educação de Surdos (ICES) e ao Centro de Referência em Educaçáo e Atendimento Especializado do Estado do Ceará (CREAECE). 


\section{Resultados e discussão}

O jogo "Conhecendo o mundo invisível - desafio de sinais" trata-se de uma proposta alternativa aos professores, para informar e esclarecer alunos, matriculados no Ensino Fundamental, com surdez, sobre algumas doenças causadas por micro -organismos, utilizando ferramentas visuais, como o desenho e a expressão corporal. Bem como, ao inserir, nas peças do jogo, sinais de Libras, procuramos aproximar à cultura do aluno com surdez ao conhecimento microbiano, despertando neles a curiosidade em utilizar o jogo como instrumento pedagógico.

\section{Componentes do jogo didático}

Os componentes do jogo foram escolhidos atendendo aos critérios de fácil manuseio, uso de material reciclado, visando estimular o aluno à valorização do meio ambiente, e adequação a faixa etária que se destina (a partir de dez anos de idade), sendo constituído de: um tabuleiro, uma ampulheta, cinquenta cartas, dois dados, quatro pinos, um bloco para desenhos e um folheto de instruçóes (figura 1).

Em relação ao tabuleiro (figura 1.A), este possui tamanho A3 e impressão colorida em papel $80 \mathrm{Kg}$ plastificado. As informaçóes contidas nele são: cinco imagens das faces do dado referente aos temas; seis imagens das faces do dado referentes aos números de casas que cada equipe poderá avançar em caso de êxito na resposta; os nomes das dez doenças abordadas nas cartas e o percurso que as equipes realizarão até alcançarem a casa "chegada" vencendo o jogo.

O número de casas do tabuleiro corresponde a uma sugestão de utilização do jogo por um tempo médio de trinta a cinquenta minutos, dependendo do desenvolvimento de cada partida e como o professor aprofundará o conteúdo. As cartas (figura 1.G) que contém o conteúdo do jogo apresentam na face da frente o tema, e em seu verso a resposta final (nome da doença), o tipo de micro-organismo (apenas com caráter informativo) e a informação facilitadora do desenho/mímica, possuindo tamanho $8 \mathrm{~cm} \times 6 \mathrm{~cm}$, impressão colorida em papel $40 \mathrm{Kg}$ plastificado. A utilização de imagens dos micro-organismos, provenientes de sites de pesquisa da internet, teve como objetivo proporcionar aos usuários do jogo a visualização microscópica desses agentes, o que em geral é pouco viabilizado nas escolas pela carência de recurso, fato relatado por Cassanti (2007), ao afirmar que a Microbiologia fica retida muitas vezes ao abstrato. Objetivou-se também atrair o interesse dos alunos pela variedade de formas e cores.

Os dois dados (figura 1.B) que foram personalizados com sinais de Libras desempenham funçôes importantes durante a realização das partidas. $\mathrm{O}$ primeiro está relacionado com o sorteio do tema que será trabalhado pela equipe, possuindo cinco faces com os sinais das letras iniciais de cada tema e uma face com o símbolo de "proibido", que significa que a equipe perderá a vez na rodada. Nâo sendo utilizado, este dado quando a equipe estiver na casa "escolha o tema". O segundo dado possui seis faces, nas quais em cada uma há um sinal de Libras dos números decimais (um a seis), correspondendo ao critério inicial de ordem entre as equipes e ao número de casas que as equipes poderão avançar em caso de êxito em sua resposta. 
Os outros componentes são: uma ampulheta (figura 1.C), que marca aproximadamente um minuto e quinze segundos para resposta de cada pergunta; quatro pinos de material plástico (nas cores amarelo, azul, verde e vermelho - figura 1.D), que representam as equipes durante a partida; um bloco para desenhos (figura 1.E) de tamanho A5, constituído de papel reciclado e encadernado em espiral com duzentas folhas, não sendo acompanhado de lápis ou caneta para execução dos desenhos; e uma caixa de papeláo reaproveitada (figura 1.F), com medidas de $36 \mathrm{~cm}$ x $23 \mathrm{~cm}$ x 07 $\mathrm{cm}$ e personalização referente ao nome e imagens das peças do jogo.

As instruçôes para utilização do jogo foram disponibilizadas em um folheto explicativo, que discrimina: peças, objetivos, preparação, como jogar (rodada inicial e seguintes), regras gerais e informaçóes complementares.

Figura 1 - Componentes do jogo "Conhecendo um mundo invisível - desafio de sinais". Legenda: A-Tabuleiro, B- Face dos dados, C- Ampulheta, D- Pinos, E- Bloco de desenhos, F- Caixa do jogo; G - Frente e verso de uma carta.
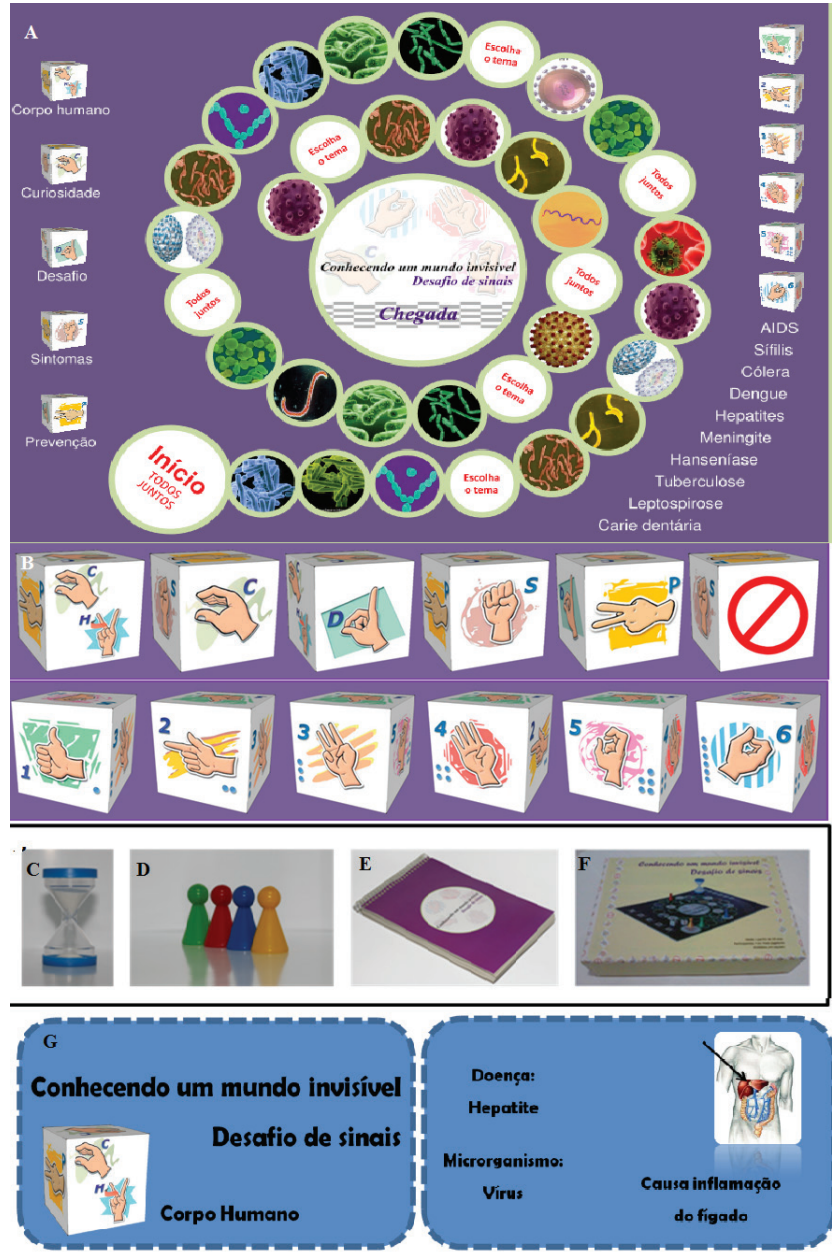


\section{Conteúdo do jogo didático e os PCNs}

O resultado final apresenta uma relação entre dois objetivos do PCN e a aplicação do jogo didático (quadro 1). O primeiro aspecto é de que os conteúdos devem favorecer a construçáo, pelos estudantes, de uma visão de mundo como um todo formado por elementos inter-relacionados, entre os quais o ser humano, é um agente de transformação. Isso se verifica neste jogo, pela quantidade de informaçóes que demonstram a importância das atitudes do homem.

Os outros aspectos são de que os conteúdos devem ser relevantes dos pontos de vista social, cultural e científico, permitindo ao estudante compreender, em seu cotidiano, as relaçóes entre o ser humano e a natureza, e que devem se constituir em fatos, conceitos, procedimentos, atitudes e valores a serem promovidos de forma compatível com as possibilidades e necessidades de aprendizagem do estudante, de maneira que ele possa operar com tais conteúdos e avançar efetivamente nos seus conhecimentos (BRASIL, 1998).

Quadro 1 - Objetivos do PCN e a aplicação no jogo.

\begin{tabular}{l|l}
\hline \multicolumn{1}{c|}{ Objetivo } & \multicolumn{1}{c}{ Aplicaçáo no jogo } \\
\hline $\begin{array}{l}\text { Os alunos devem desenvolver a habilidade de } \\
\text { saber utilizar diferentes fontes de informação e } \\
\text { recursos tecnológicos para adquirir e construir } \\
\text { conhecimentos. }{ }^{1}\end{array}$ & $\begin{array}{l}\text { O jogo é considerado como um veículo de } \\
\text { informação, com o diferencial de ser atrativo e } \\
\text { prazeroso aos alunos. }\end{array}$ \\
\hline $\begin{array}{l}\text { Os alunos devem utilizar as diferentes lingua- } \\
\text { gens, entre elas a gráfica e a corporal, como } \\
\text { meio para produzir, expressar e comunicar } \\
\text { suas ideias, atendendo a diferentes intençóes e } \\
\text { situações de comunicaçáo. }\end{array}$ & $\begin{array}{l}\text { A forma de utilização proposta neste jogo } \\
\text { (expressão corporal e gráfica), formas de } \\
\text { linguagens que proporcionam um maior } \\
\text { envolvimento entre o sujeito que transmite e } \\
\text { o que recebe a informaçáo. Isso está de acordo } \\
\text { com Moraes e Lima (2002), ao afirmarem } \\
\text { que os alunos devem ser sujeitos ativos de sua } \\
\text { aprendizagem. }\end{array}$ \\
\hline
\end{tabular}

Fonte: BRASIL, 1998.

O conteúdo do jogo foi distribuído em cinco categorias de temas (corpo humano, curiosidade, desafio, sintomas e prevenção), nos quais estão presentes as informaçôes de dez doenças microbianas (Dengue, Cárie Dentária, Cólera, Hepatite, Hanseníase, Meningite, AIDS, Sífilis, Tuberculose e Leptospirose). Os temas estão relacionados, principalmente, a outros dois objetivos do Ensino Fundamental, segundo os PCN's de Ciências Naturais (quadro 2).

O primeiro é que os alunos devem conhecer o próprio corpo e como dele cuidar, através da valorizando e adoção de hábitos saudáveis como um dos aspectos básicos da qualidade de vida, agindo com responsabilidade em relação à sua saúde e à saúde coletiva, enquanto o segundo objetivo, que está estritamente relacionado com os temas, é o da importância do aluno perceber-se integrante, dependente e agente transformador do ambiente, identificando seus elementos e as interaçóes entre eles, e dessa forma, contribuir ativamente para a melhoria deste meio (BRASIL, 1998). 
Quadro 2 - Objetivos do Ensino Fundamental e a aplicação no jogo.

\begin{tabular}{l|l}
\hline \multicolumn{1}{c|}{ Objetivo do ensino fundamental } & \multicolumn{1}{c}{ Aplicação no jogo } \\
\hline $\begin{array}{l}\text { Os alunos devem conhecer o próprio corpo e } \\
\text { como dele cuidar. }\end{array}$ & $\begin{array}{l}\text { Nas cartas de tema "corpo humano" que os } \\
\text { alunos utilizem a informação dos órgãos e } \\
\text { líquidos corporais atingidos por determinada } \\
\text { doença, passando-se a trabalhar conteúdos de } \\
\text { anatomia humana, e proporcionando ao aluno } \\
\text { um maior conhecimento sobre seu corpo. } \\
\text { Da mesma forma, quando são abordados os } \\
\text { diversos sinais provocados pelas doenças no } \\
\text { tema "sintomas", e quais as medidas para } \\
\text { se evitar a ocorrência das mesmas, no tema } \\
\text { "prevenção", visa despertar para a adoção de } \\
\text { hábitos saudáveis. }\end{array}$ \\
\hline $\begin{array}{l}\text { A importância de o aluno perceber-se inte- } \\
\text { grante, dependente e agente transformador do } \\
\text { ambiente. }{ }^{1}\end{array}$ & $\begin{array}{l}\text { Nas informaçôes sobre as formas de trans- } \\
\text { missão das doenças, os alunos podem se } \\
\text { identificar como integrantes de um mundo } \\
\text { feito por diversas formas de vida, e perceber a } \\
\text { intensidade de integraçóes que existem entre } \\
\text { nós humanos, os outros animais e os seres mi- } \\
\text { croscópicos, entendendo que nossas atitudes } \\
\text { podem influenciar direta ou indiretamente na } \\
\text { ocorrência da transmissão dessas doenças. }\end{array}$ \\
\hline
\end{tabular}

Fonte: BRASIL, 1998.

Enquanto os eixos temáticos dos PCN's de Ciências Naturais do Ensino Fundamental representam uma organização articulada de diferentes conceitos, procedimentos, atitudes e valores para cada um dos ciclos de escolaridade, compatível com os critérios de seleção acima mencionados (BRASIL, 1998).

Nesse sentido, o jogo "Conhecendo um mundo invisível - desafio de sinais" está inserido particularmente em três desses eixos, sendo eles: Vida e Ambiente, Ser Humano e Saúde e Tecnologia e Sociedade (quadro 3). 
Quadro 3 - Eixos do PCN e aplicaçóes no jogo.

\begin{tabular}{|c|c|c|}
\hline Eixo & Recomendação & Aplicação \\
\hline Vida e Ambiente & $\begin{array}{l}\text { Conhecimento sobre a } \\
\text { diversidade da vida }\end{array}$ & Micro-organismos \\
\hline \multirow{6}{*}{ Ser Humano e Saúde } & $\begin{array}{l}\text { Concepção de ser humano } \\
\text { como um todo }\end{array}$ & $\begin{array}{l}\text { Locais atingidos pelas doenças } \\
\text { e formas de transmissáo }\end{array}$ \\
\hline & $\begin{array}{l}\text { Manutenção da saúde } \\
\text { (sexualidade) }\end{array}$ & AIDS e Sífilis \\
\hline & $\begin{array}{l}\text { Fatores relacionados aos } \\
\text { problemas de saúde }\end{array}$ & $\begin{array}{l}\text { Informações sobre prevenção } \\
\text { e formas de transmissão }\end{array}$ \\
\hline & $\begin{array}{l}\text { Nomes de doenças, agentes e } \\
\text { sintomas }\end{array}$ & Seleção de dez doenças \\
\hline & $\begin{array}{l}\text { Ideias e valores aprendidos } \\
\text { informalmente a respeito do } \\
\text { corpo }\end{array}$ & $\begin{array}{l}\text { Desmistificação de conceitos } \\
\text { e noçôes de informaçôes } \\
\text { importantes }\end{array}$ \\
\hline & $\begin{array}{l}\text { Automedicação como fator de } \\
\text { risco à vida }\end{array}$ & $\begin{array}{l}\text { Orientação ao uso de } \\
\text { prescrição médica }\end{array}$ \\
\hline Tecnologia e Sociedade & $\begin{array}{l}\text { Despertar a curiosidade em } \\
\text { conhecer através da pesquisa }\end{array}$ & $\begin{array}{l}\text { Transmissão de doenças atra- } \\
\text { vés da água e alimentos }\end{array}$ \\
\hline
\end{tabular}

O eixo Vida e Ambiente busca promover a ampliação do conhecimento sobre a diversidade da vida nos ambientes naturais ou transformados pelo ser humano, estudando a dinâmica da natureza e como a vida se processa em diferentes espaços e tempos (BRASIL, 1998). Neste contexto, o jogo proposto é uma sugestáo de material didático para ampliar o conhecimento dos alunos sobre os micro-organismos, seres tão diminutos, que necessitariam de técnicas e recursos materiais para serem visualizados através dos métodos tradicionais, que de acordo com o Silva, Oliveira e Souza (2009), faz com que o ensino acaba por se dar de forma defasada.

Já o eixo temático Ser Humano e Saúde, o qual desenvolve as relaçóes entre as condiçôes do ambiente e a manutenção da saúde, se constitui no principal eixo norteador do jogo proposto. A concepção de corpo humano como um todo, um sistema integrado de outros sistemas, que interage com o ambiente e que reflete a história de vida do sujeito está descrita tanto nas cartas de informaçóes sobre os locais do corpo atingidos pelas doenças, quanto nas formas de transmissão.

Por fim, o eixo Tecnologia e Sociedade apresenta questóes como o saneamento dos espaços urbanos e rurais, a conservação de alimentos, a produção de bens de consumo, as tecnologias ligadas à medicina e ao lazer (BRASIL, 1998). Esses estudos estabelecem conexão entre este eixo e o tema transversal Saúde, ao analisar diferentes aspectos que contribuem para a saúde do indivíduo e das populaçóes.

Despertar a curiosidade dos alunos em conhecer melhor esses aspectos através do incentivo a pesquisa em sala de aula, quando são, por exemplo, abordados concei- 
tos como a transmissão de doenças através da água ou alimentos contaminados, pode se configurar como uma alternativa para a necessidade de aperfeiçoar o processo de ensino em sala de aula, de acordo com Engel, Blackwell e Miniard (2000).

\section{Considerações finais}

A construção do jogo "Conhecendo um mundo invisível - desafio de sinais" e sua aplicação como recurso de valor pedagógico, contribui para melhor entendimento sobre a necessidade de elaboração e aplicação de práticas educacionais que despertem o interesse dos alunos em aprender, demonstrando ser o jogo didático uma importante ferramenta para esse processo.

No tocante ao conteúdo abordado, destacou-se que os Parâmetros Curriculares Nacionais para Ciências Naturais do Ensino Fundamental se apresentaram como um documento norteador fundamental, bem como a exploração de conteúdos relacionados à saúde se mostra importante em uma época na qual o mundo está com um nível de globalizaçáo tấo grande, que o surgimento de uma doença em determinado local, pode levar a sua expansão, tomando enormes proporçóes, e atingindo milhares de pessoas. Por tanto, o conhecimento sobre a existência e importância dos micro-organismos, confere grande relevância aos assuntos de Ciências relacionados à Microbiologia. E introduzir essas questóes ainda no Ensino Fundamental é buscar a formaçáo de adultos mais conscientes de seu papel na sociedade.

Acreditamos que a disponibilizaçáo desse jogo é uma boa sugestáo de abordagem de conteúdo, trabalhado de modo menos abstrato e mais atraente aos alunos cegos, se constituindo em uma possibilidade de trabalhar temas previstos no currículo de Ciências de maneira a subsidiar o processo de ensino aprendizagem voltado para a alfabetização científica e a apropriação de conhecimentos relacionados ao desenvolvimento de competências e habilidades, bem como oferecer uma alternativa lúdica e adaptada para a educação dos cegos, minimizando a distância ainda existente entre o ensino regular desses alunos, quando comparado a alunos sem deficiências visuais.

\section{Referências}

ANTUNES, C. Jogos para estimulaçáo das múltiplas inteligências. 17 ed. Petrópolis: Vozes, 2010.

BRASIL. Lei Federal no 9394/96, de 20 de dezembro de 1996. Estabelece as Diretrizes e Bases da Educaçáo Nacional. Diário Oficial da Uniăo, Ano CXXXIV, n. 248, 23 de dezembro de 1996. Brasília. 1996.

BRASIL. Ministério da Educação. Brasília (Org.). Parâmetros Curriculares Nacionais: ciências naturais. Brasília: Secretaria da Educação Fundamental. 1998. 138 p.

CASSANTI, A. C. Microbiologia Democrática: estratégias de ensino-aprendizagem e formaçấo de professores. Disponível em: <http://www.conhecer.org.br/enciclop/2008/microbiologia1.pdf>. Acesso em: 18 out. 2010.

COUTO, R. M. S.; PORTUGAL, C. Jogo para auxiliar o letramento bilíngue de crianças surdas. In: Anais do Congresso Internacional de Design, Lisboa: 2006.

DECHIHCI, C.; SILVA, L. C.; GOMIDE, A. B. Projeto incluir: acesso e permanência na UFU. In: DECHIHCI, C.; SILVA, L. C. Inclusáo escolar e educaçáo especial: teoria e prática na diversidade. Uberlândia: EDUFU, 2008, p. 333-351.

DOHME, V. Atividades lúdicas na educaçáo: o caminho de tijolos amarelos do aprendizado. Petrópolis: Vozes. 2003. 
ENGEL, J. F.; BLACKWELL, R. D.; MINIARD, P. W. Comportamento do consumidor. 8. ed. Rio de Janeiro: LTC, 2000.

FERREIRA, M.E.S.; PHILIPPSEN, H. K.; ROCHA, C. A. M.; Prática lúdica em Microbiologia para alunos do Ensino Fundamental. 58 Reunião Anual da SBPC - Florianópolis, SC, 2006.

MOURÃO, C. I.; CAETANO, E. P. A importância de utilização de jogos e modelos didáticos no ensino de Microbiologia. In: 25 CONGRESSO BRASILEIRO DE MICROBIOLOGIA, 2009. Anais... Porto de Galinhas: Pernambuco, 2009

NERI, M. C.; SOARES, W. L. Idade, incapacidade e o número de pessoas com deficiência. Revista Brasileira de Estudos de Populaçáo, Campinas, 2004, v. 21, n. 2, p. 303-321.

NICOLAU, C. R.; BOAS, D. M. V. Análise do jogo microligue: o jogo das associaçóes, na introdução da Microbiologia no Ensino Fundamental. In: II ENCONTRO REGIONAL SUL DE ENSINO DE BIOLOGIA, 2006, Santa Catarina. Anais... Florianópolis, 2006.

OLIVEIRA, E. C. de. Jogos na educação de surdos: proposta de uso de objetos de aprendizagem. In: V ENCONTRO DE PESQUISA EM EDUCAÇÃO DE ALAGOAS, 2010, Maceió. Pesquisa em Educação: Desenvolvimento, Ética e Responsabilidade Social. Anais... Alagoas. 2010. Disponível em: <http://dmd2. webfactional.com/media/anais/JOGOS-NA-EDUCACAO-DE-SURDOS-PROPOSTA-DE-USO-DE-OBJETOS-DE-APRENDIZAGEM.pdf>. Acesso em: 5 out. 2011.

SAMPIERI, R. H.; COLLADO, C. F.; LUCIO, P. B. Metodologia de pesquisa. 3 ed. São Paulo: McGraw -Hill. 2006. 583 p.

SILVA, L. O.; OLIVEIRA, R. A. S.; SOUZA, R. R. A possibilidade de ensinar Microbiologia nas escolas sem laboratório. Saúde e Ambiente em Revista. v. 4, n. 2. 2009.

TORTORA, G. J; FUNKE, B. R.; CASE, C. L. Microbiologia. Porto Alegre: Artmed. 2005.

\section{Correspondência}

Roberta Silva Rizzo - Rua Augusto César Luitgards Moura, 1714, CEP 69307-275, Boa Vista, Roraima, Brasil.

E-mail: robertasilvarizzo@gmail.com - lydiapantoja@yahoo.com.br - jeannepontes@yahoo.com.br - germanapaixao@terra.com.br

Recebido em 05 de novembro de 2013

Aprovado em 12 de março de 2014 